reduction in the forced expiratory volume in one second after exercise was calculated using the preexercise value as the baseline value.

Statistical significance was calculated with Student's paired $t$ test. The study was approved by the research ethical committee of the Faculty of Medicine, Queen's University, Belfast.

The table shows the percentage reduction in forced expiratory volume in one second with and without using the mask. Only one patient (case 6) showed no improvement with the mask. The mean reduction in the group was $33 \cdot 7 \%$ (SE $3 \cdot 2 \%$ ) without the mask and $9 \cdot 1 \%(6 \cdot 1 \%)$ with it $(\mathrm{p}<0 \cdot 01)$. Most patients felt heat on their face but none complained of difficulty in breathing through the mask.

\section{Comment}

Our results show that a mask retaining heat and moisture effectively controlled exercise induced asthma in most of our asthmatic subjects. Previous work has shown that humidification of air can prevent the reduction in the forced expiratory volume. ${ }^{1}$ Storing exhaled air in a mask such as the one we used is a practical way to humidify and heat air, thus making both water and heat available for the next inspiration. The mask might be more beneficial in cold weather, which classically precipitates the development of exercise induced asthma. ${ }^{+}$The increased dead space from the mask does not play an important part during exercise.

We found that even with the mask the forced expiratory volume in one second decreased by $9 \cdot 1 \%$ after exercise. This reduction is, however, similar
Reduction in forced expiratory volume in one second $\left(F E V_{l}\right)$ after exercise with and without a mask in 10 asthmatic patients

\begin{tabular}{|c|c|c|c|c|c|c|}
\hline \multirow[b]{2}{*}{ Case No } & \multirow[b]{2}{*}{$\begin{array}{c}\text { Age } \\
\text { (years) }\end{array}$} & \multirow[b]{2}{*}{ Sex } & \multirow[b]{2}{*}{$\begin{array}{l}\text { Type of } \\
\text { exercise }\end{array}$} & \multirow{2}{*}{$\begin{array}{c}\text { Duration of } \\
\text { exercise }\end{array}$} & \multicolumn{2}{|c|}{ Reduction in $\mathrm{FEV}_{1}(\%)$} \\
\hline & & & & & $\begin{array}{l}\text { With } \\
\text { mask }\end{array}$ & $\begin{array}{l}\text { Without } \\
\text { mask }\end{array}$ \\
\hline 1 & 21 & $M$ & Treadmill & $12 \mathrm{~min}$ & 30 & 25 \\
\hline 2 & 18 & $\mathrm{~F}$ & Treadmill & $10 \mathrm{~min}$ & 31 & 8 \\
\hline 3 & 22 & $M$ & Treadmill & $13 \min 15 \mathrm{~s}$ & 52 & 9 \\
\hline 4 & 31 & $\mathrm{~F}$ & Treadmill & $9 \min 50 \mathrm{~s}$ & 39 & $0^{\star}$ \\
\hline 5 & 33 & $\mathrm{~F}$ & Treadmill & $7 \min 4 s$ & 23 & 9 \\
\hline 6 & 33 & $M$ & Cycle & $4 \min 12 s$ & 28 & 31 \\
\hline 7 & 12 & $\mathrm{~F}$ & Cycle & $3 \min 5 s$ & 31 & 14 \\
\hline 8 & 12 & $M$ & Cycle & $6 \mathrm{~min}$ & 43 & 36 \\
\hline 9 & 36 & $\mathrm{~F}$ & Treadmill & $6 \min 30 s$ & 18 & 0 \\
\hline 10 & 30 & $\mathrm{~F}$ & Treadmill & $8 \min 30 s$ & 42 & $0^{\star \star \star}$ \\
\hline
\end{tabular}

¿Improved $17 \%$.

$\star \star$ Improved $24 \%$

to that produced by sodium cromoglycate, ${ }^{5}$ which has been used for more than 20 years in treating exercise induced asthma. $\beta_{2}$ Agonists often completely abolish the drop in forced expiratory volume, but in some athletic contexts their stimulant effects may be disadvantageous. Masks may be helpful in the management of subjects who cannot or will not take prophylactic drug treatment.

1 Chen WY, Horton DJ. Heat and water loss from the airways and exerciseinduced asthma. Respiration 1977;34:305-13.

Anderson SD. Is there a unifying hypothesis for exercise induced asthma? f Allergy Clin Immunol 1984;73:660-5.

3 Evaluation report. Heat and moisture exchangers. $\mathcal{F}$ Med Eng Technol 1987;11: $117-27$.

4 Strauss RH, McFadden ER, Ingram RH, Jaeger JJ. Enhancement of exercise induced asthma by cold air breathing. N Engl f Med 1977;297:743-7.

5 Chan-Yeung $M$. The effect of Sch 1000 and disodium chromoglycate on exercise induced asthma. Chest 1977;71:320-3.

(Accepted 1 October 1991 )
Department of

Therapeutics, University

Hospital, Nottingham

NG7 2UH

P D E Jones, PHD, research

fellow

$\mathrm{N}$ Hudson, $\mathrm{MB}$, research

fellow

C J Hawkey, DM, professor of gastroenterology

Correspondence to:

Professor Hawkey.

$B M \mathcal{F} 1992 ; 304: 480-1$

\section{Depression of salivary epidermal growth factor by smoking}

\author{
P D E Jones, N Hudson, C J Hawkey
}

Smoking is associated with the development of peptic ulceration, retarded ulcer healing, and enhanced ulcer relapse.' The mechanisms by which these associations arise are, however, unclear. Epidermal growth factor is a polypeptide secreted into saliva which stimulates epithelial proliferation, protects the mucosa against acute injury, and heals gastric and duodenal ulcers in both animals and humans. ${ }^{2}$ We have shown that output of salivary epidermal growth factor is diminished in patients with rheumatoid arthritis taking non-steroidal, anti-inflammatory drugs, ${ }^{3}$ a group prone to gastric ulceration. We investigated whether smoking might likewise be associated with reduced secretion of epidermal growth factor.

\section{Patients, methods, and results}

Patients attending for endoscopy over 26 months were interviewed and studied in the fasting state before endoscopy. Demographic information recorded included age, sex, smoking status (current smoker, exsmoker, never smoked), drug use, and history. On the basis of current or previous endoscopic findings patients were categorised as having gastric or duodenal ulceration, oesophageal ulceration or benign oesophageal stricture, or no upper gastrointestinal disease. Patients with other, miscellaneous, or mixed conditions were excluded from analysis, as were those taking nonsteroidal, anti-inflammatory drugs or drugs known to affect salivary flow.

Salivary flow was stimulated by the lingual appli- cation of citric acid. Saliva collected by aspiration with a dental sucker over 10 minutes was frozen and epidermal growth factor concentration measured using a radioreceptor assay. ${ }^{3}$ Results were logarithmically transformed to obtain a normal distribution and subjected to analysis of variance with comparison by $t$ test where significant differences were indicated.

\section{Results}

Satisfactory samples were obtained from 336 patients with normal findings on endoscopy (175) or ulceration (161). Overall the 222 current non-smokers (ex smokers and those who had never smoked) secreted a mean of $49.9 \mathrm{ng}$ of epidermal growth factor per 10 minutes ( $95 \%$ confidence interval 44.3 to $56 \cdot 2 \mathrm{ng} / 10 \mathrm{~min}$ ), and $95(43 \%)$ of them had ulcers. The 114 current smokers secreted $30.6(25 \cdot 1$ to $37 \cdot 3) \mathrm{ng}$ of growth factor $10 \mathrm{~min}$ $(\mathrm{p}<0.001)$ and a larger proportion of them $(64 ; 56 \%)$ had ulcers. Differences between current smokers and non-smokers remained significant when patients with duodenal ulceration and gastric ulceration were analysed separately (table)

To exclude the possibility that differences arose by confounding, patients who were current smokers were

Output of salivary epidermal growth factor in smoking and nonsmoking subgroups. Results are means (95\% confidence intervals)

\begin{tabular}{|c|c|c|c|c|c|}
\hline \multirow{2}{*}{$\begin{array}{l}\text { Endoscopic } \\
\text { findings }\end{array}$} & \multicolumn{2}{|c|}{ Non-smokers } & \multicolumn{2}{|r|}{ Smokers } & \multirow[b]{2}{*}{$\mathrm{p}$ Value } \\
\hline & No & $\mathrm{ng} / 10 \mathrm{~min}$ & No & $\mathrm{ng} / 10 \mathrm{~min}$ & \\
\hline Normal & 125 & $\begin{array}{c}53 \cdot 0 \\
(45 \cdot 2 \text { to } 62 \cdot 2)\end{array}$ & 50 & $\begin{array}{c}34 \cdot 8 \\
(29 \cdot 7 \text { to } 40 \cdot 9)\end{array}$ & $<0.001$ \\
\hline Duodenal ulcer & 50 & $\begin{array}{c}50.9 \\
(40.9 \text { to } 63.5)\end{array}$ & 36 & $\begin{array}{c}27 \cdot 1 \\
(17 \cdot 7 \text { to } 41 \cdot 5)\end{array}$ & 0.006 \\
\hline Gastric ulcer & 28 & $\begin{array}{c}54 \cdot 6 \\
(40 \cdot 1 \text { to } 74 \cdot 3)\end{array}$ & 22 & $\begin{array}{c}25 \cdot 5 \\
(14 \cdot 6 \text { to } 44 \cdot 8)\end{array}$ & 0.013 \\
\hline Oesophageal ulcer & 19 & $\begin{array}{c}45 \cdot 6 \\
(30 \cdot 3 \text { to } 68 \cdot 7)\end{array}$ & 6 & $\begin{array}{c}28 \cdot 2 \\
(16 \cdot 3 \text { to } 48 \cdot 7)\end{array}$ & NS \\
\hline
\end{tabular}


compared, using paired $t$ tests, with those who were current non-smokers, individually matched for age (to within 5 years), sex, and diagnosis. One hundred and eight matches were successfully obtained. Epidermal growth factor output for smokers was $64 \%(44.0$ to $92.2 \%)$ of the value for non-smokers $(\mathrm{p}<0.05)$ in 60 control pairs and $43 \%(28.3$ to $64 \cdot 8 \%)$ of the value for non-smokers $(\mathrm{p}<0.01)$ in 48 pairs of patients with ulcers.

\section{Comment}

Our data show that smoking is associated with reduced salivary secretion of epidermal growth factor and an increased prevalence of peptic ulceration in patients attending for endoscopy. Cigarette smoking could thus predispose to peptic ulcer by depressing salivary secretion of epidermal growth factor. Depression of submandibular epidermal growth factor concentration in a small group of patients with gastric and duodenal ulcers has been reported. ${ }^{4}$ Our data suggest that reductions in epidermal growth factor secretion in patients with ulcers are likely to be attributable to the higher proportion of patients with ulcers who are smokers.

Smoking is associated with depressed prostaglandin

synthesis, while nicotine can enhance platelet aggregation, vasoconstriction, and increased concentrations of circulating catecholamines. ${ }^{5}$ Carbon monoxide may depress oxygen transport. ${ }^{5}$ However, neither the mediator nor the mechanism by which smoking depresses production of salivary epidermal growth factor is clear. Epidermal growth factor is produced by Brunner's glands in the duodenum, as well as by a cell lineage which develops at the site of gastrointestinal ulceration. If smoking also depresses local mucosal synthesis or secretion of epidermal growth factor this might represent an additional factor predisposing to duodenal ulceration as well as a plausible explanation for the link between smoking and Crohn's disease.

1 Sontag S, Graham DY, Belsito A, Weiss J, Farley A, Grunt R, et al. Cimetidine, cigarette smoking, and recurrence of duodenal ulcer. $N$ Engl $f \mathrm{Med}$ 1984;311:689-93.

2 Olsen PS, Poulsen SS, Therkelson K, Nexø E. Effect of sialoadenectomy and synthetic human urogastrone on healing of chronic gastric ulcer in rats. Gut 1986;27:1443-9.

3 Jones PDE, Daneshmend TK, Bossingham DH, Swannell AJ, Doherty M, Hawkey CJ. Reduced production of salivary epidermal growth factor in rheumatoid patients. European f Gastroenterol Hepatology 1990;2:203-7.

4 Maccini DM, Veit BC. Salivary epidermal growth factor in patients with and without acid peptic disease. Am f Gastroenterol 1990;85:1102-4.

5 Benowitz NL. Clinical pharmacology of nicotine. Ann Rev Med 1986;37:21-32.

(Accepted 10 September 1991)

\title{
Safety of subaqua diving with a patent foramen ovale
}

\author{
Stephen J Cross, Sian A Evans, Lesley F \\ Thomson, Hai Shiang Lee, Kevin P Jennings, \\ Thomas G Shields
}

\section{Department of \\ Cardiology, Aberdeen \\ Royal Infirmary, Aberdeen \\ AB9 2ZD \\ Stephen J Cross, MRCP, registrar \\ Hai Shiang Lee, MRCP, registrar \\ Kevin P Jennings, FRCP, consultant}

Hyperbaric Medicine Unit, Aberdeen Royal Infirmary Sian A Evans, BM, senior house officer

Lesley F Thomson, MB, senior house officer

Thomas G Shields, FRCP, consultant

Correspondence to: Dr Cross.

BMF 1992;304:481-2
Patent foramen ovale may be a risk factor for developing some forms of decompression sickness. ${ }^{12}$ Venous nitrogen bubbles are thought to evade the pulmonary filter by passing through these intracardiac shunts and to form emboli, which enlarge to cause symptoms. Should potential and current divers be screened for the presence of a patent foramen ovale, and if one is found should they be prevented from diving?

\section{Subjects, methods, and results}

Seventy eight subaqua divers who had not had any form of decompression sickness were examined by contrast echocardiography.

Microbubble contrast was generated in $8-10 \mathrm{ml}$ of agitated normal saline by the two syringe and three way tap method. ${ }^{3}$ This contrast medium was injected rapidly into a right antecubital vein while an apical four chamber view of the heart was being observed with a Vingmed CFM 700 imaging system.

Up to six injections of contrast medium were given: three during quiet respiration and three during the strain phase of a Valsalva manoeuvre. A patent foramen ovale was said to be present if contrast medium was seen in the left heart within five cardiac cycles of the right heart becoming opaque. The procedure was stopped if a patent foramen ovale was shown or after the sixth injection.

Twenty four divers were found to have a patent foramen ovale and another two late (presumed intrapulmonary $)^{4}$ shunts. These divers were recreational (16), professional (six), or a mixture of the two (four). The professional group comprised police (two), biologists (four), fish farmers (two), and ex-Royal Navy divers (two) (table).

All subjects claimed in general to control their decompression profiles by using conventional tables or decompression computers. Nine of the professional and five of the amateur divers admitted to having performed dives with factors possibly associated with an increased risk of developing decompression sickness.

The diving record of one former professional diver

Comparison of professional and amateur divers with demonstrable right to left shunts. Values are means $(S D)$

\begin{tabular}{lcc}
\hline & $\begin{array}{c}\text { Professional } \\
(\mathbf{n}=10)\end{array}$ & $\begin{array}{c}\text { Amateur } \\
(\mathbf{n}=16)\end{array}$ \\
\hline Age (years) & $35 \cdot 9(7 \cdot 1)$ & $32 \cdot 7(8 \cdot 2)$ \\
No of years diving & $12 \cdot 8(10 \cdot 9)$ & $7 \cdot 5(5 \cdot 8)$ \\
No of dives & $650(446)$ & $236(316)$ \\
\hline
\end{tabular}

in particular was notable. He had been diving for 30 years, including some time as an experimental diver with the Royal Navy. He had a large shunt demonstrable on the first injection of contrast medium - that is, without a provocative manoeuvre having been performed. He had performed 637 dives with compressed air to a maximum depth of $60 \mathrm{~m}, 141$ closed circuit oxygen dives, 327 dives with nitrogen-oxygen, 14 surface oriented dives to $100 \mathrm{~m}$ with helium-oxygen, and 47 bell dives to $180 \mathrm{~m}$ with helium-oxygen. He had spent 1743 days in saturation at an average depth of $200 \mathrm{~m}$ (maximum $330 \mathrm{~m}$ ). All this was in addition to a "large number" of emergency mine disposal dives (recorded in a missing log book). He had not experienced any form of decompression sickness.

\section{Comment}

As patent foramen ovale might be related to some forms of decompression sickness, ${ }^{12}$ the question arises whether these shunts are relevant in subjects who have not had decompression sickness.

Although the dive profiles tended to vary between this particular group of professional and amateur divers (the professional divers tended to perform shallower multiple dives, with frequent ascents for any one dive), most had a substantial exposure to diving over several years. None had decompression sickness. Nevertheless, we found a $31 \%$ incidence of patent foramen ovale (or a $33 \%$ incidence of right to left 